\title{
Six year longitudinal study of respiratory function in dairy farmers in the Doubs province
}

\author{
J-C. Dalphin*, M.F. Maheu*, A. Dussaucy+, D. Pernet*, J-C. Polio*, A. Dubiez*, \\ J-J. Laplante**, A. Depierre*
}

Six year longitudinal study of respiratory function in dairy farmers in the Doubs province. J-C. Dalphin, M.F. Maheu, A. Dussaucy, D. Pernet, J-C. Polio, A. Dubiez, J-J. Laplante, A. Depierre. CERS Journals Ltd 1998.

ABSTRACT: A previous study, carried out in 1986 in France, showed the prevalence of respiratory symptoms and of respiratory function impairment to be higher in dairy farmers than in a control group of nonexposed subjects living in a rural zone. In order to confirm the harmful effect of dairy farming, the two groups were re-studied 6 yrs later at the same period of the year.

One hundred and ninety-four $(\mathbf{7 7 . 6 \%})$ farmers and $155(62 \%)$ control subjects were available for re-examination. Non-re-evaluated subjects were comparable to reevaluated subjects for age, sex, smoking and respiratory symptoms and function at initial evaluation.

Dairy farmers consistently had more respiratory symptoms and lower levels of respiratory function than did control subjects. In the study populations as a whole, the mean annual decline in vital capacity (VC) and forced expiratory volume in one second (FEV1) was slightly, but nonsignificantly, higher in farmers than in control subjects: in $\mathrm{mL} \cdot \mathrm{yr}^{-1}(\mathrm{sD}),-43.1(68.2)$ versus $\mathbf{- 3 7 . 9}(60.2)$ for $\mathrm{VC}$ and $\mathbf{- 3 2 . 8}(56.7)$ versus $\mathbf{- 3 0}$ (47.2) for FEV1. There was a positive interaction between farming and age (i.e. duration of exposure in this cohort) on respiratory function decline, and in male subjects aged Š45 yrs, dairy farming was associated with an accelerated loss in $\mathrm{VC}(\mathrm{p}<0.05)$ and FEV1 $(p<0.05)$ after controlling for age, smoking, height and geographic location in a multiple linear regression model. Initial values of respiratory function, age and pack-years smoked (only for VC) were the other variables found to be significant determinants of decline in lung function.

In conclusion, this study mainly suggests that dairy farming is associated to a very moderate accelerated loss in respiratory function that increases with duration of exposure and is significant in older male subjects.

Eur Respir J 1998; 11: 1287-1293.
*Dept of Chest Disease, + ${ }^{+}$Dept of Epidemiology, University of Besançon, Besançon, France, and **Medical Dept of the Mutualité Sociale Agricole of the Doubs, Besançon, France.

Correspondence: J-C. Dalphin

Dept of Chest Disease

Hôpital Saint Jacques

2 Place Saint Jacques

25000 Besançon

France

Fax: 33381811999

Keywords: Dairy farmers

farming

longitudinal study

respiratory function

Received: May 51997

Accepted after revision March 11998

Supported by grant no. 92CN08 from the "Institut National de la Santé et de la Recherche Médicale", France.
Many clinical and epidemiological studies listed in recent reviews [1-3] have highlighted close associations between acute or chronic respiratory diseases and agricultural occupational exposure. This is especially the case for grain workers $[4,5]$ and swine farmers [6], in whom a risk of chronic airway obstruction has been demonstrated or strongly suspected.

Dairy farmers have been less extensively studied. In Finland, the annual incidence of chronic bronchitis appears to be higher in farmers than in nonfarmer control subjects [7]. Cross-sectional studies with control groups have suggested that dairy farmers have a moderate, but significant, alteration of their expiratory flow rate [8-10]; however, such results have not been confirmed by other studies [11, 12] and, to our knowledge, no longitudinal study of respiratory function has been conducted in dairy farmers.

In the Doubs, a damp and rainy semi-mountainous region of France, most of the agricultural activity is devoted to dairy farming. In order to obtain the quality stamp for milk and cheeses, most farmers do not use silo feeds or cereal or flour feeds. Moreover, chemical fertilizers and pesticides are not used. Thus, hay and micro-organisms inside constitute the principal occupational exposure. A cross-sectional study conducted in this region and in this agricultural context showed that the prevalence of respiratory symptoms and of respiratory function impairment was significantly higher in a group of dairy farmers than in a control group of nonexposed subjects living in a rural zone [8]. To confirm the possible risk of chronic pulmonary disease in these farmers, the population initially investigated in 1986 was re-evaluated in 1992 in order to compare the prevalence of respiratory symptoms and especially the changes in respiratory function parameters in the two groups.

\section{Methods}

The study was conducted in cooperation with the Doubs Mutualité Sociale Agricole (MSA) (national health insurance for farmers) whose medical department organizes annual free check-ups for all of their members (farmers and 
agricultural administrative employees). These examinations are performed in the morning, in premises close to the subject's home. Approximately 15 subjects can be examined per morning.

\section{Population}

The study population in 1986 consisted of two groups of subjects of both sexes, between the ages of 20-60 yrs, living in five districts of a rural zone in the Doubs province, selected from MSA medical files: a group of 250 exclusive dairy farmers and a control group of 250 nonexposed, agricultural administrative employees. The method of selection of these two groups of subjects was described previously [8]. The control group consisted of all the nonexposed agricultural administrative employees from the five districts. The population of dairy farmers from the five districts involved 1,026 subjects aged 16-65 yrs; 912 farmers $(88.9 \%)$ participated in the MSA physical examinations. Farmers $<20$ yrs and $>60$ yrs were excluded because there were no age-matched control subjects in the administrative population. A subgroup of 250 farmers was then composed and matched to the 250 nonexposed rural administrative employees on the basis of age, sex, height and smoking habits. The respiratory symptoms and function of the two groups were compared; the characteristics of the initial population and the results of the cross-sectional comparisons are described in our previous study [8] and are not shown here.

In 1992, each subject was asked individually to submit to the same investigations as those performed 6 yrs earlier. An explanatory letter concerning the objectives of the study and its practical value was sent to each subject. Subjects who agreed to participate in the study were asked to attend the MSA check-ups, at the same period of the year as 6 yrs previously. Subjects who refused to participate in the study were contacted by telephone in order to obtain information about the reasons for their refusal.

The MSA tried to obtain information about the subjects failing to reply or who had changed address. According to the same methodology as that used 6 yrs previously, the two groups of subjects participating in the study were compared on the basis of medical and occupational questionnaires and respiratory function tests.

\section{Questionnaires}

Medical questionnaires were sent by mail and collected during the check-up examinations. They were read and completed, when necessary (in the case of missing data), by the same investigator as 6 yrs previously (D. Pernet). This questionnaire included information concerning personal and demographic identification, smoking habits, respiratory and cardiovascular history and a respiratory symptom inventory. Questions concerning respiratory symptoms were based on the American Thoracic Society questionnaire [13]. The basis of this questionnaire was the same as that used in 1986. Symptoms analysed were defined as follow:

1) Chronic bronchitis: cough and daily expectoration 3 months $\cdot \mathrm{yr}^{-1}$ for two consecutive years, with the exclusion of patients with a past history of bronchiectasis, pulmo- nary tuberculosis, or severe infantile respiratory infection(s).

2) Dyspnoea: shortness of breath when hurrying on level ground or walking up a slight hill.

3) Acute bronchitis: the question in the questionnaire was: "Do you often have acute bronchitis? If so, how many times per year? For how many years?". Subsequent questions were designed to define symptoms, with a particular emphasis on the purulence of sputum during episodes of acute bronchitis. Acute bronchitis was considered to be recurrent when more than two episodes per year had occurred within the last 2 yrs.

Nonsmokers (NS) were defined as those having smoked on average less than one cigarette, one cigar, or one pipe a day for a year. Current smokers (CS) smoked this amount or more, and exsmokers (ES) had stopped smoking at least 1 month before the time at which they filled out the questionnaire.

\section{Respiratory function tests}

The same pneumotachograph (Autospiro Minato AS 500, Medical Science Company Ltd, Osaka, Japan) as that used in 1986 according to recent recommendations at that time [14] was used to measure the following parameters: vital capacity (VC), forced expiratory volume in one second (FEV1), forced mid-expiratory flow (FEF25-75\%) and peak flow (PF). A minimum of three adequate measurements was obtained in each subject. The best values were selected after correction to body temperature, pressure system (BTPS). All measurements were made by the same investigator. For cross-sectional comparisons, the values were expressed as a percentage of the European Coal and Steel Community (ECSC) predicted values, calculated in relation to sex, age and height [15].

\section{Data analysis}

Firstly, a cross-sectional analysis of the 1992 data was performed using univariate and multivariate statistics. Odds ratios for respiratory symptoms in farmers as compared to control subjects were estimated using the logistic regression analysis. The odds ratios were adjusted for age (in four classes, <35, 35-44, 45-54, >54), sex (male, female), smoking habits (CS, ES, NS) and geography (plain=0, tableland=1). A multiple linear regression model was used to estimate the effect of dairy farming on percentage predicted values of respiratory function parameters adjusted for smoking habits (pack-yrs smoked) and geography.

Secondly, a longitudinal analysis was performed. The two groups were compared for annual decline of respiratory function parameters (1992 value - 1986 value/number of years between the two visits) with adjustment for 1992 values of age (yrs), height $(\mathrm{cm})$, sex (female $=0$, male $=1$ ), pack-yrs smoked and geography (plain=0, tableland=1) by multiple linear regression. Changes in smoking habits between 1986 and 1992 were taken into account in the regression model by using the smoking status in two classes (current smokers or not) in 1986 and 1992. The initial respiratory values (1986) and mean respiratory values between 1986 and 1992 [16] were also tested in the model. We used ANOVA (first level interaction) to test the interactions between exposure (the fact of being a farmer) and 
the following factors on the decline in respiratory function: sex (male versus female), age ( $\breve{S} 45$ yrs versus $<45$ yrs) and smoking (current smokers versus others).

Data analysis was performed using the BMDP statistical software package (BMDP, Los Angeles, CA, USA). Standard statistical methods used included chi-squared, ANOVA and Fisher's exact test for univariate analyses; interactions between significant covariates were tested. An adjustment in multivariate models was made, including potential confounders known to be determinants of respiratory function. $\mathrm{p}$-values $ð 0.05$ were regarded as significant. Assumption for residual normality was assessed by normal probability plot of the residuals.

\section{Results}

\section{Description of the population}

In 1986, there were 250 subjects in each group. We were able to recontact 220 farmers and 186 controls, of whom 206 and 157, respectively, accepted the principle of the study. One hundred and ninety four $(77.6 \%)$ farmers and 155 controls $(62 \%)$ were actually examined. Twenty six farmers and 31 controls, theoretically able to be reevaluated, did not participate in the study, either because they did not feel concerned (eight farmers and 13 controls), or for medical reasons (eight farmers and five controls), or for other reasons including unexplained refusal (10 farmers and 13 controls). The respiratory function tests of four farmers and 17 control subjects were retrospectively considered to be inadequate according to the criteria adopted and were not taken into account for the longitudinal analysis. The individual characteristics, frequency of respiratory symptoms and respiratory function in 1986 in subjects re-evaluated and not re-evaluated are shown in table 1 . The number of subjects lost for the second evaluation was higher in the control group than in the exposed group $\left(\mathrm{p}<10^{-4}\right)$ and in the plain than in the tableland $\left(p<10^{4}\right)$. There was no difference between subjects re-evaluated and not re-evaluated for respiratory symptoms or respiratory function.

The two groups of re-evaluated subjects (farmers and controls) remained comparable for sex, age (mean age and the four age classes), height and smoking habits (pack-yrs smoked and the three smoking classes). Conversely, the two groups were not comparable for geographical location: a majority of control subjects lived in the plain $\left(\mathrm{p}<10^{-3}\right)$. Twelve farmers $(5.7 \%)$ and 16 control subjects (10.3\%) started smoking between 1986 and 1992 (Ns); five farmers $(2.5 \%)$ and one control subject $(0.5 \%)$ stop-ped smoking between 1986 and 1992 (Ns). Thirty one of the 194 farmers were officially retired in 1992, but 27 of them continued to work by helping their spouse or children.

\section{Cross-sectional analysis}

The main results of the cross-sectional analysis are summarized in tables 2 and 3. As in 1986, the prevalence of chronic bronchitis, acute recurrent bronchitis and dyspnoea was higher in farmers than in control subjects with an adjusted odds ratio (confidence interval at 95\%) of 3.29 (1.38-7.84), 2.84 (1.08-7.37) and 3.69 (2.11-6.42), respectively. All the respiratory function parameters were lower in farmers than in control subjects with significant statistical differences after adjustment for confounders (table 3 ). Other results from the multiple linear regression analysis (not shown in the tables) demonstrated that there were significant negative correlations between age and \% VC

Table 1. - Demographic, clinical and spirometric characteristics in 1986 for re-evaluated and non-re-evaluated farmers and control subjects

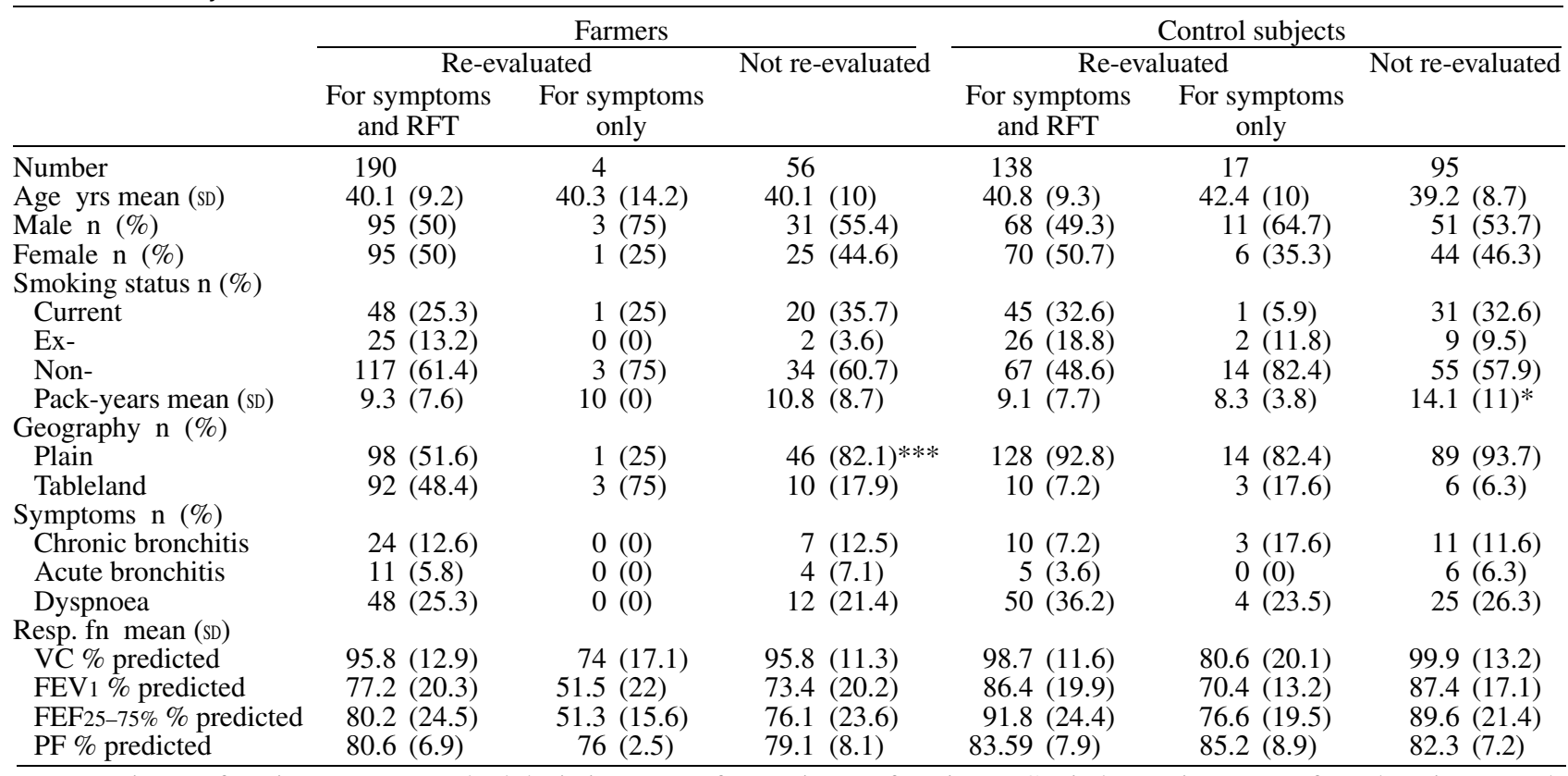

RFT: respiratory function test; sD: standard deviation. Resp. fn: respiratory function; VC: vital capacity; FEV1: forced expiratory volume in one second; FEF25-75\%: forced mid-expiratory flow; PF: peak flow. *: p<0.05; ***: p<0.001; in each group (farmers and control subjects), not re-evaluated are compared to re-evaluated subjects, except for RFT (re-evaluated for RFT versus others). 
Table 2. - Prevalence of respiratory symptoms in 1992

\begin{tabular}{lccccc}
\hline & $\begin{array}{c}\text { Farmers } \\
(\mathrm{n}=194)\end{array}$ & $\begin{array}{c}\text { Controls } \\
(\mathrm{n}=155)\end{array}$ & OR* $^{*}$ & $95 \%$ CI & p-value $^{+}$ \\
\hline Chronic bronchitis n $(\%)$ & $25(12.9)$ & $10(6.5)$ & 3.29 & $1.38-7.84$ & $<0.01$ \\
Acute bronchitis n $(\%)$ & $20(10.3)$ & $6(3.8)$ & 2.84 & $1.08-7.37$ & $<0.05$ \\
Dyspnoea n $(\%)$ & $71(36.6)$ & $22(14.2)$ & 3.69 & $2.11-6.42$ & $<10^{-4}$ \\
\hline
\end{tabular}

*: Odds ratio (OR) with confidence interval (CI) at $95 \%$ for farmers versus controls adjusted for age, sex, smoking status and geography from logistic regression. +: Wald's statistic for logistic regression.

$(\mathrm{p}<0.001), \% F^{2} V_{1}(\mathrm{p}<0.01)$ and \%FEF25-75\% $(\mathrm{p}<0.05)$, and between smoking and \%FEV1 $(\mathrm{p}<0.05)$ and \%FEF25$75 \%(\mathrm{p}<0.05)$.

\section{Longitudinal analysis}

The $6 \mathrm{yr}$ changes in respiratory function in the two groups are shown in table 4 . The mean annual declines in VC and FEV1 were higher in farmers than in control subjects, but the differences were not statistically significant

Table 3. - Spirometric characteristics* in 1992 for farmers and controls

\begin{tabular}{llll}
\hline & $\begin{array}{c}\text { Farmers } \\
(\mathrm{n}=194)\end{array}$ & $\begin{array}{l}\text { Controls } \\
(\mathrm{n}=155)\end{array}$ & $\mathrm{p}$-value $^{+}$ \\
\hline Available data $\mathrm{n}$ & 190 & 138 & \\
$\begin{array}{l}\text { VC \% predicted (SD) } \\
\text { FEV1 \% predicted (SD) }\end{array}$ & $\begin{array}{l}98.9(13.3) \\
88.9(14.9)\end{array}$ & $96.2(12.5)$ & 0.33 \\
$\begin{array}{l}\text { FEF25-75\% } \\
\text { \% predicted (SD) }\end{array}$ & $80.5(25.7)$ & $90.7(28.5)$ & 0.0013 \\
PF \% predicted (SD) & $80.5(22.1)$ & $92(20.05)$ & 0.017 \\
\hline
\end{tabular}

VC: vital capacity; FEV1: forced expiratory volume in one second; FEF25-75\%: forced mid-expiratory flow; PF: peak flow. *: Results are expressed as mean percentage (SD) of theoretical values (European Coal and Steel Community) calculated in relation to age, sex and height. +: Wald's statistic for exposure coefficient (controls $=0$, farmers $=1$ ) in multiple linear regression adjusted for smoking habits and geography.

Table 4. - Mean annual decline (AD) in respiratory function parameters between 1986 and 1992

\begin{tabular}{|c|c|c|c|}
\hline & $\begin{array}{l}\text { Farmers } \\
(\mathrm{n}=190)\end{array}$ & $\begin{array}{l}\text { Controls } \\
(\mathrm{n}=138)\end{array}$ & p-value ${ }^{+}$ \\
\hline AD VC mL·yr-1 (SD) & $-43.1(68.2)$ & $-37.9(60.2)$ & 0.075 \\
\hline AD FEV1 $\mathrm{mL} \cdot \mathrm{yr}^{-1}(\mathrm{SD})$ & $-32.8(56.7)$ & $-30.0(47.2)$ & 0.10 \\
\hline AD FEF $25-75 \% \mathrm{~mL} \cdot \mathrm{yr}^{-1}(\mathrm{SD})$ & $-23.8(120)$ & $-27.1(156)$ & 0.60 \\
\hline $\mathrm{AD}$ PF $\mathrm{mL} \cdot \mathrm{yr}^{-1}(\mathrm{SD})$ & $13.6(275)$ & $49.2(300)$ & 0.0022 \\
\hline
\end{tabular}

after adjustments for the potential confounders. PF values improved in both groups, with a better improvement in the control group $(\mathrm{p}<0.01)$. An analysis of first level interaction by ANOVA showed a significant positive interaction between exposure and age Š 45 yrs $(\mathrm{p}<0.05)$, and a nearly significant positive interaction between exposure and males $(\mathrm{p}=0.07)$. These findings led us to analyse specifically the subgroup of male subjects aged $\breve{S} 45$ yrs; in this subgroup, the mean annual decline in $\mathrm{VC}$ and $\mathrm{FEV} 1$ were significantly higher in farmers than in control subjects, in $\mathrm{mL}$. $\mathrm{yr}^{-1}$ (sD), VC: -73 (77) versus -53 (80) $(\mathrm{p}<0.05)$, FEV1: -59 (77) versus $-34(66)(\mathrm{p}<0.01)$, respectively. The same level of statistical significance was observed both without adjustment and with adjustment for smoking, height and geographical location.

The final multiple linear regression included initial values of respiratory function, age, sex, height, smoking status, geography and exposure (farmers versus control subjects) (table 5). Initial values of respiratory function parameters, age, height, pack-yrs smoked (only for VC) and exposure were positively correlated with the decline in respiratory function. When initial values of respiratory function were excluded from the model or were replaced by mean respiratory function values, the correlation between farming and decline in respiratory function became nonsignificant.

\section{Discussion}

This study shows that in 1992 as well as in 1986, farmers had more respiratory symptoms and a lower respiratory function than control subjects living in rural zones. The respiratory function of these farmers deteriorated slightly more rapidly than that of the control subjects, with a significant difference in older male subjects.

This type of study, based on populations of workers, is potentially subject to a number of biases. It is unlikely that any measuring biases affected this study for the following

Table 5. - Multiple regression models for annual decline (AD) of vital capacity (VC) and forced expiratory volume in one second (FEV1)

\begin{tabular}{|c|c|c|c|c|}
\hline Variable & $\begin{array}{l}\text { AD VC mL } \cdot \mathrm{yr}^{-1} \\
\text { Coefficient (SE) }\end{array}$ & p-value + & $\begin{array}{l}\text { AD FEV1 } \mathrm{mL} \cdot \mathrm{yr}^{-1} \\
\text { Coefficient }(\mathrm{sE})\end{array}$ & p-value $^{+}$ \\
\hline Intercept & $-236.1(111.9)$ & 0.036 & $-223.2(96.87)$ & 0.022 \\
\hline Initial value & $-0.05(0.007)$ & $<10^{-4}$ & $-0.03(0.007)$ & $<10^{-3}$ \\
\hline Age & $-2.50(0.42)$ & $<10^{-4}$ & $-1.50(0.37)$ & $10^{-4}$ \\
\hline Sex & $-8.68(10.40)$ & 0.40 & $4.51(8.73)$ & 0.61 \\
\hline Height & $3.01(0.71)$ & $<10^{-4}$ & $1.98(0.62)$ & 0.002 \\
\hline Pack-years smoked & $-1.10(0.52)$ & 0.036 & $-0.50(0.45)$ & 0.26 \\
\hline Smoker in 1986 & $10.73(12.62)$ & 0.40 & $13.71(10.87)$ & 0.21 \\
\hline Smokers in 1992 & $6.12(11.94)$ & 0.61 & $-2.84(10.29)$ & 0.78 \\
\hline Geography & $5.75(4.12)$ & 0.16 & $8.58(3.57)$ & 0.02 \\
\hline Exposure $\#$ & $-13.29(7.58)$ & 0.023 & $-14.18(6.59)$ & 0.03 \\
\hline & $\mathrm{R}^{2}=0.20$ & & $\mathrm{R}^{2}=0.10$ & \\
\hline
\end{tabular}

SE: Standard error; +: Wald's statistic, all variables listed were included simultaneously in the models; each coefficient and $\mathrm{p}$-value is controlled for all other variables. \#: Controls $=0$; farmers $=1$. 
reasons. The questionnaire used in 1992 was the same as that used in 1986. Respiratory function tests were performed according to the ATS recommendations [14], with the same pneumotachograph and by the same investigator as in 1986. There are probably seasonal variations of respiratory function in farmers, related to their occupational activities [17], which is why farmers were examined during the same season as 6 yrs previously. Finally, as in 1986, all subjects were examined by spirometry in the morning, between 08:30 and 11:30 h.

However, the possibility of a selection bias must be considered. The "healthy worker effect" and a selective loss of less healthy workers are less likely to occur in this study than in studies concerning salaried farmers, who are often submitted to employment medical examinations. Our population was composed of owner-farmers (with their spouses) operating small farms handed down from father to child. Farmers leave their work only when forced by serious medical problems. It is possible, nevertheless, that the most robust of the farmer's children tends to take over the family farm. However, should this potential bias exist, it would only underestimate the difference in terms of symptoms and respiratory function observed between the two groups studied.

These two groups were comparable for the classical confounding factors (age, sex and smoking). However, other factors related to respiratory function such as alcohol consumption and serum $\alpha 1$-antitrypsin were not evaluated in this study. Nevertheless, a recent study in the same region, designed to investigate the risk of asthma and atopy in dairy farmers, showed that farmers had the same alcohol consumption as a group of nonfarmer control subjects living in a rural zone.

The control subjects were agricultural administrative employees (local branch of the "National Health Insurance for Farmers" (MSA), agricultural banks, "Regional and Provincial Chambers of Agriculture", etc.) with no occupational exposure; they lived and/or worked in villages or small towns with little or no industrial or environmental pollution. Many of them ( $20 \%)$ according to an estimation from MSA-nevertheless belonged to farming families and had been exposed during their childhood or youth to agricultural antigens; it is unlikely that this factor significantly affected the results, but it cannot be totally excluded, especially as the respiratory function of these control subjects was slightly lower than normal values (table 3). The mean annual decline of their respiratory flows was also similar to that considered classic in healthy subjects [18].

This study, which monitored the course of respiratory parameters in two groups of age-matched subjects, examined at the same time, over a relatively brief period ( $6 \mathrm{yrs})$, has a low risk of being affected by a "cohort effect" [19, 20]; it has been noted that respiratory function appears to have improved over the years and that the low function of the elderly subjects may reflect adverse events earlier in their lives rather than an accumulation of the declines with age. If it exists in our study, this "cohort effect" would affect the two groups similarly. The average values of PF were better in 1992 than in 1986. This improvement of PF is unlikely to be due to a "learning effect" [18] in that subjects were tested only twice at a $6 \mathrm{yr}$ interval. Nevertheless, as for the "cohort effect", should this "learning effect" exist, it would logically concern both groups in the same way.

The results of this study (the two cross-sectional steps and the longitudinal follow-up) are consistent: all respiratory parameters were altered in the same direction and less favourably in farmers. This consistency argues significantly in favour of the existence of a risk of chronic pulmonary impairment in dairy farmers. Nevertheless, the decline in respiratory function in farmers was moderate and not very different from that observed in control subjects, in contrast with the very significant difference observed in the initial study conducted in 1986 [8]. The decline in lung function was not statistically different between the two groups after adjustments for age, sex, height, smoking and geography; geography was taken into account because previous studies suggested an influence on respiratory status in farmers $[21,22]$. After including the initial values (1986) of respiratory function in the regression model, significant differences in decline in respiratory function appeared (table 5). In such a study with only two measurements of respiratory function, adjusting for initial values is very questionable. It can make the results difficult to interpret due to the inclusion of a variable that is both dependent and independent in the model. Moreover, when baseline lung function differs alot from one group to the other, as it does in our study, adjusting for initial values could lead to overestimating the difference in decline in lung function between the two groups. We therefore prefer to consider that, in the studied population as a whole, the annual loss in lung function does not differ statistically between farmers and control subjects.

There is, however, an accelerated loss in lung function in older male farmers, which is statistically significant (without taking into account baseline lung function). In this subgroup, the annual decline in FEV1 was nearly twice as high as in farmers $\left(-59 \mathrm{~mL} \cdot \mathrm{yr}^{-1}\right.$ versus $\left.-34 \mathrm{~mL} \cdot \mathrm{yr}^{-1}\right)$. Nevertheless, a greater deleterious longitudinal effect of farming was to be expected given the cross-sectional results. The respiratory function of the farmers may have been slightly underestimated on the two cross-sectional measurements as the respiratory function tests were performed after most of the farmers had been significantly exposed while foddering or milking between $06: 30 \mathrm{~h}$ and 08:30 h. Studies in grain farmers [23-25] and swine farmers [26] have demonstrated the possibility of a significant drop in respiratory flow after exposure to organic dusts. However, these work-shift decrements in FEV1 are moderate and involve a minority of subjects. It is therefore unlikely that this phenomenon, should it exist in dairy farming, plays a significant role in our study. It is our opinion that this discrepancy can be explained to a large extent by the fact that the farmers' respiratory function had deteriorated very significantly before 1986 . Indeed, exposure to organic dusts has decreased with time in our region.

Recent studies conducted in dairy farmers in the Doubs have shown that modernization of farms, especially barndrying of fodder (which has been developed over the last $15 \mathrm{yrs}$ ), has been accompanied by a reduction of exposure to airborne micro-organisms (especially thermophilic $A c$ tinomycetes) and that farmers operating modern farms with this type of fodder drying for a long time have had a better respiratory function than other farmers [27, 28]. It is therefore possible that the harmful effect of fodder farming exposure on respiratory function was at its highest 
point 15 yrs ago or more and that the older subjects (especially the males who have been exposed more), who have worked in worse conditions for a long period, have retained the sequelae of this exposure and to this day present an abnormally rapid decline in respiratory function. The study by KENNEDY et al. [29], which indicates that im-provement in lung function did not occur in grain workers after retirement argues favourably for our hypothesis.

Smoking is known to be the major risk factor in the decline of respiratory function. In our study, the effect of smoking was low (significant only in the decline of VC) (table 5). This has already been observed in longitudinal studies in working populations $[30,31]$ and in the elderly [32], and may reflect the "healthy smoker effect" [33], i.e. the possibility that subjects who start and who continue to smoke are particularly resistant to the effects of cigarette smoke. However, PAHWA et al. [22] observed that in grain workers, the effect of smoking on respiratory function decline disappeared in subjects exposed for $>20 \mathrm{yrs}$ in industry. In our study as well, all the farmers were exposed for a long time because they were born on the farm. However, it is also possibly due to the fact that our population contained few smokers $(20 \%)$ and, more especially, these subjects were light smokers with an average of 10 pack-yrs in 1986 [8]. The observed effect of age is difficult to interpret because all the farmers have been exposed since childhood; it is, therefore, not possible to differentiate the effect of age from that of the duration of exposure. Moreover, the cumulative exposure was not precisely evaluated in this study. Nevertheless, the observed effect of age is very important and, in our opinion, is probably largely due to an effect of the duration of exposure, as was previously observed in grain workers $[22,30]$.

Taken together, these cross-sectional and longitudinal data support the theory that dairy farming represents a risk of chronic respiratory symptoms and of moderately accelerated decline in lung function that particularly concerns the older subjects. Further studies are necessary to correlate respiratory status to precise indicators of quantitative and qualitative exposure. This will be more difficult in this agricultural sector, where the population is dispersed and the exposure is different from one farm to another, than in other conditions such as grain or swine production.

Acknowledgements: The authors thank D. Debieuvre, B. Toson, J.F. Pugin who participated in the collection of the data and I. Brohet, A. Tarallo and N. Peuteuil for their technical assistance.

\section{References}

1. Zedja JE, Dosman JA. Respiratory disorders in agriculture. Tubercle Lung Dis 1993; 74: 74-86.

2. Malmberg P. Health effect of organic dust exposure in dairy farmers. Am J Ind Med 1990; 17: 7-15.

3. Merchant JA. Agricultural exposures to organic dusts. Occup Med 1987; 2: 409-425.

4. Chan-Yeung M, Enarson DA, Kennedy SM. The impact of grain dust on respiratory health. Am Rev Respir Dis 1992; 145: 476-487.

5. Chan-Yeung M, Dimich-Ward H, Enarson DA, Kennedy SM. Five cross-sectional studies of grain elevator workers. Am J Epidemiol 1992; 136: 1269-1279.
6. Donham KJ. Health effect from work in swine confinement buildings. Am J Ind Med 1990; 17: 17-25.

7. Husman K, Koskenvuo M, Kaprio J, Terho EO, Vohlohnen I. Role of environment in the development of chronic bronchitis. Eur J Respir Dis 1987; 71: Suppl. 152, 5763.

8. Dalphin JC, Bildstein F, Pernet D, Dubiez A, Depierre A. Prevalence of chronic bronchitis and respiratory function in a group of dairy farmers in the French Doubs province. Chest 1989; 95: 1244-1247.

9. Heller RF, Hayward DM, Farebrother MTB. Lung function of farmers in England and Wales. Thorax 1986; 41: 117-121.

10. Babbott FL Jr, Gump DW, Sylwester DL, MacPherson BV, Holly RC. Respiratory symptoms and lung function in a sample of Vermont dairymen and industrial workers. Am J Public Hlth 1980; 70: 241-245.

11. Rautalahti M, Terho EO, Vohlonen I, Nuutinen J, Husman K, Korhonen O. Effect of indoor feeding season for cattle on lung function of dairy farmers. Eur J Respir Dis 1987; 71: 188-196.

12. Malmberg P, Rask-Andersen A, Palmgren U, Höglund S, Kolmodin-Hedman B, Stalenheim G. Exposure to microorganisms, febrile and airway-obstructive symptoms, immune status and lung function of Swedish farmers. Scand $J$ Work Environ Hlth 1985; 11: 287-293.

13. Ferries BG. Epidemiology standardization project. Am Rev Respir Dis 1978; 119 (Suppl.): 7-55.

14. American Thoracic Society. Standardization of spirometry. 1987 update. Am Rev Respir Dis 1987; 136: 12851298.

15. Quanjer $\mathrm{PhH}$, ed. Standardized Lung Function Testing. Report Working Party Standardization of Lung Function Tests, European Community for Coal and Steel. Bull Eur Physiopath Respir 1983; 19 (Suppl. 5): 1-95.

16. Humerfelt S, Gulsvik A, Skjaerven R, et al. Decline in FEV1 and airflow limitation related to occupational exposures in men of an urban community. Eur Respir J 1993; 6: 1095-1103.

17. Hensley MJ, Scicchitano R, Saunders NA, et al. Seasonal variation in non-specific bronchial reactivity: a study of wheat workers with a history of wheat associated asthma. Thorax 1988; 43: 103-107.

18. Fletcher CM, Peto R, Tinker CM, Speizer FE. The Natural History of Chronic Bronchitis and Emphysema. London, Oxford University Press, 1976.

19. Burrows B, Lebowitz MD, Camilli AE, Knudson RJ. Longitudinal changes in forced expiratory volume in one second in adults. Methodological considerations and findings in healthy nonsmokers. Am Rev Respir Dis 1986; 133: 974-980.

20. Glindmeyer HW, Diem JE, Jones RN, Weill H. Non comparability of longitudinally and cross-sectionally determined annual change in spirometry. Am Rev Respir Dis 1982; 125: 544-548.

21. Dalphin JC, Devieuvre D, Pernet P, et al. Prevalence and risk factors for chronic bronchitis and farmer's lung in French dairy farmers. Br J Ind Med 1993; 50: 941944.

22. Pahwa P, Senthilselvan A, McDuffie HH, Dosman JA. Longitudinal estimates of pulmonary function decline in grain workers. Am J Respir Crit Care Med 1994; 150: 656-662.

23. Corey P, Hutcheon M, Broder I, Mintz S. Grain elevator workers show work-related pulmonary function changes and dose-effect relationships with dust exposure. $\mathrm{Br}$ I Ind Med 1982; 39: 330-337. 
24. doPico G, Reddan W, Anderson S, Flaherty D, Smalley E. Acute effects of grain dust exposure during a work shift. Am Rev Respir Dis 1983; 128: 399-404.

25. Chan-Yeung M, Schulzer M, MacLean L, Dorken E, Erzybowski S. Epidemiologic health survey of grain elevator workers in British Columbia. Am Rev Respir Dis 1980; 121: 329-338.

26. Reynolds SJ, Donham KJ, Whitten P, Merchant JA, Burmeister LF, Popendorf WJ. Longitudinal evaluation of dose-response relationships for environment exposures and pulmonary function in swine production workers. $\mathrm{Am}$ J Ind Med 1986; 29: 33-40.

27. Dalphin JC, Pernet D, Reboux G, et al. Influence of mode of storage and drying of fodder on thermophilic actinomycete aerocontamination in dairy farms in the Doubs region of France. Thorax 1991; 46: 619-623.

28. Dalphin JC, Polio JC, Pernet D, et al. Influence of barn drying of fodder on respiratory symptoms and function in dairy farmers of the Doubs region of France. Thorax 1994; 49: 50-53.
29. Kennedy SM, Dimich-Ward H, Desjardins A, Kassam A, Vedal S, Chan-Yeung M. Respiratory health among retired grain elevators workers. Am J Respir Crit Care Med 1994; 150: 59-65.

30. Tabona M, Chan-Yeung M, Enarson D, Mclean L, Dorken E, Schulzer M. Host factors affecting longitudinal decline in lung spirometry among grain elevator workers. Chest 1984; 85: 782-786.

31. Frew AJ, Kennedy SM, Chan-Yeung M. Methacholine responsiveness, smoking, and atopy as risk factor for accelerated FEV1 decline in male working populations. Am Rev Respir Dis 1992; 146: 878-883.

32. Villar MTA, Dow L, Coggon D, Lampe FC, Holgate ST. The influence of increased bronchial responsiveness, atopy, and serum IgE on decline in FEV1: a longitudinal study in the elderly. Am J Respir Crit Care Med 1995; 151: 656-662.

33. Becklake MR, Lalloo U. The "healthy smoker": a phenomenon of health selection? Respiration 1990; 57: 137 144. 